\title{
Komplikasi Kehamilan dan Anemia Kehamilan Meningkatkan Insidensi Perdarahan Pascasalin (Studi Kasus Kontrol)
}

\author{
Pregnancy Complications and Increasing Pregnancy Anemia \\ Incidence of Postpartum Hemorrhage \\ (Case Control Study) \\ Firda Fibrila $1, \bowtie$ \\ ${ }^{1}$ Jurusan Kebidanan Politeknik Kesehatan Tanjung Karang, Indonesia \\ ${ }^{\square}$ Corresponding author: firdafibrila@poltekkes-tjk.ac.id
}

\begin{abstract}
Kata kunci:
Perdarahan pascasalin, komplikasi hehamilan, anemia.
\end{abstract}

Keyword:

Pos partum hemorrhage, complications of

pregnancy, anemia.

\begin{abstract}
Abstrak
Latar Belakang: Perdarahan pasca salin sebagai penyebab kematian ibu yang pertama. Tujuan: Penelitian ini bertujuan untuk mengetahui faktor risiko terjadinya kasus perdarahan pascasalin di Rumah Sakit Umum Ahamad Yani Metro. Metode: Penelitian ini menggunakan rancangan case control study dengan dimensi retrospektif. Kasus adalah perdarahan pascasalin ibu bersalin. Jumlah sampel dengan perbandingan kelompok kasus dan kelompok kontrol adalah $1: 1$ atau 86 : 86. Pengumpulan data menggunakan kuesioner bentuk check list untuk memperoleh variabel penelitian meliputi usia, paritas, komplikasi kehamilan, anemia, berat janin (variabel independen) dan perdarahan pascasalin (variabel dependen). Data dianalisis dengan analisis univariat dan analisia bivariat dengan uji chi-square. Hasil: Hasil penelitian menunjukkan ada hubungan komplikasi kehamilan $(p$-value $=0,049 ; \mathrm{OR}=1,927)$, anemia $(p$-value $=0,000 ; \mathrm{OR} 5,031)$ dengan perdarahan pascasalin. Simpulan: Faktor komplikasi kehamilan dan anemia meningkatkan terjadinya perdarahan pascasalin. Perlu upaya antenatal care mendeteksi dini dan penanganan komplikasi kehamilan dan anemia, sehingga perdarahan pasca salin dapat dicegah.
\end{abstract}

\begin{abstract}
Background: Postpartum hemorrhage is the first cause of maternal death. Purpose: This study aims to determine the risk factors for postpartum hemorrhage cases at Ahmad Yani Metro General Hospital. Methods: This study used a case control study design with a retrospective dimension. Case is postpartum maternal bleeding. The number of samples with a comparison of case groups and control groups is 1: 1 or $86: 86$. Data collection uses a checklist form questionnaire to obtain research variables including age, parity, pregnancy complications, anemia, fetal weight (independent variable) and postpartum hemorrhage (variable dependent). Data were analyzed by univariate analysis and bivariate analysis with the chi-square test. Results: The results showed there was a relationship between pregnancy complications ( $p$-value $=0.049 ;$ OR $=1,927)$, anemia $(p$-value $=$ 0,000; OR 5,031) with postpartum hemorrhage. Conclusion: Pregnancy complications and anemia factors increase the occurrence of postpartum hemorrhage. Antenatal care needs to be detected early and handling complications of pregnancy and anemia, so that post-saline bleeding can be prevented.
\end{abstract}

Copyright $@ 2018$ Jurnal Kesehatan Metro Sai Wawai. All rights reserved 


\section{Pendahuluan}

Perdarahan pasca salin merupakan kasus kegawat daruratan obstetri. Kasus ini merupakan lima penyebab utama kematian ibu di negara berpenghasilan tinggi dan rendah per kapita. Jumlah kasus perdarahan pasca salin di negara berkembang sebanyak 1 orang dalam 1000 kelahiran (Belfort, 2017). Survey Demografi Kesehatan Indonesia (SDKI) tahun 2012 melaporkan, kematian ibu di Indonesia mencapai 359 per 1000 kelahiran hidup. Angka ini meningkat jauh jika dibandingkan dengan hasil SDKI 2007 yang mencapai 228/ 100.000 kelahiran hidup.

Empat penyebab kematian ibu terbesar yaitu perdarahan 30,3\%, hipertensi dalam kehamilan (HDK) $27,1 \%$, infeksi 7,3\%, dan lain-lain yaitu penyebab kematian ibu tidak langsung seperti kondisi penyakit kanker, ginjal, jantung atau penyakit lain yang diderita ibu sebesar 35,3\%. Kasus perdarahan di Provinsi Lampung yang menyebabkan kematian mencapai 46 kasus. Sedangkan, angka kematian di kota Metro sebanyak 58,4 per 100.000 kelahiran hidup atau 2 kasus penyebab kematian ibu pada tahun 2014. Angka ini menjadi penyebab utama kematian ibu melahirkan di tahun 2015 (Kementrian Kesehatan RI, 2016).

Faktor yang mempengaruhi perdarahan pasca salin adalah faktor personal meliputi usia ibu dangeografis, faktor maternal meliputi usia kehamilan, status anemia, jenis persalinan, tindakan pada persalinan, dan komplikasi pada persalinan, dan faktor fetal meliputi tafsiran berat janin (Ononge, Mirembe, Wandabwa, \& Campbell, 2016) (Oyelese \& Ananth, 2010).

Keberhasilan penanganan kasus perdarahan pasca salin sangat tergantung dari manajemen penanganan kasus perdarahan pascasalin. Identifikasi penyebab perdarahan merupakan salah satu item penilaian dalam manajemen penanganan kasus perdarahan yang mampu membantu untuk mencegah terjadinya kasus perdarahan yang dapat mengancam kehidupan (Belfort, 2017). Penelitian ini bertujuan menganalisis faktor-faktor risiko terjadinya kasus perdarahan pascasalin. Analisis penelitian untuk melihat kemungkinan pergeseran penyebab perdarahan pascasalin.

\section{Metode}

Penelitian merupakan penelitian analitik observasional menggunakan rancangan case control study dengan dimensi retrospektif yang bersumber data sekunder dari rekam medik pada status pasien di RS Umum Jendral Ahmad Yani Kota Metro. Rancangan ini digunakan untuk menganalisis faktor risiko terjadinya kasus perdarahan pascasalin. Penelitian dilakukan di RS Umum Jendral Ahmad Yani Metro pada bulan Oktober sampai Desember 2017.

Kelompok kasus pada penelitian ini adalah perdarahan pascasalin ibu bersalin, sedangkan kelompok kontrol adalah ibu pascasalin tanpa perdarahan. Jumlah sampel berjumlah total $172 \mathrm{ibu}$ bersalin dengan perbandingan kelompok kasus dan kelompok kontrol adalah $1: 1$ atau $86: 86$. Pengmabilan sampel penelitian menggunakan teknik symple random sampling dengan diundi.

Pengumpulan data menggunakan kuesioner bentuk check list untuk memperoleh variabel penelitian meliputi usia, paritas, komplikasi kehamilan, anemia, berat janin (variabel independen) dan perdarahan pascasalin (variabel dependen). Pengumpulan data menggunakan jenis data kategori atau dikotomi. Usia dikategorikan usia berisiko ( $<20$ tahun dan $>35$ tahun) atau usia tidak beresiko ( $20-35$ tahun), Paritas dikategorikan paritas beresiko (hamil $\geq 3$ kali) atau beresiko rendah (hamil < 3 kali), Komplikasi kehamilan (placenta previa, solutio plasenta, hipertensi dan pre eklamsi) dikategorikan ya atau tidak, Anemia kehamilan $(\mathrm{Hb}<11 \mathrm{gr} \%)$ dikategorikan ya atau tidak dan Besar janin $\geq 4000$ gram dikategorikan ya atau tidak 
Data yang telah dikumpulkan dianalisis menggunakan analisis univariat berupa distribusi frekuensi. Sedangkan, analisis bivariat menggunakan uji chi-square dan fisher's exact dengan selang kepercayaan $95 \%$ dan tingkat kesalahan $(\alpha) 5 \%$.

\section{Hasil}

\section{Gambaran variabel penelitian}

Tabel 1 memperlihatkan gambaran variabel penelitian dari dari 172 responden, sebanyak 30,8\% responden usia berisiko, sebanyak 16,9\% responden paritas beresiko, sebanyak 31,4\% responden mengalami kolplikasi kehamilan, sebanyak 64\% (110) responden mengalami anemia, dan sebanyak 4,7\% responden melahirkan bayi $>4000$ gr.

Tabel 1.

Distribusi usia, paritas, komplikasi kehamilan, anemia dan berat janin

\begin{tabular}{llcc}
\hline \multicolumn{1}{c}{ Variabel Penelitian } & \multicolumn{1}{c}{ Kategori } & Jumlah & \% \\
\hline Usia & Usia beresiko $(<20$ dan $>35$ tahun $)$ & 53 & 30,8 \\
& Usia tidak beresiko $(20-30$ tahun $)$ & 119 & 69,2 \\
Paritas & Paritasberesiko $(>3)$ & 29 & 16,9 \\
\multirow{3}{*}{ Komplikasi kehamilan } & 143 & 83,1 \\
& Paritasberesikorendah $(2-3)$ & 54 & 31,4 \\
Anemia & Ada Komplikasi & 118 & 68,6 \\
& Tidak Ada Komplikasi & 110 & 64 \\
Berat janin & Anemia & 62 & 36 \\
& Tidak Anemia & 8 & 4,7 \\
& BayiBesar $(\geq 4000$ gram $)$ & 164 & 95,3 \\
\hline
\end{tabular}

\section{Analisis bivariat}

Penelitian bertujuan menganalisis faktor risiko terjadinya kasus perdarahan pascasalin selang kepercayaan 95\% dan tingkat kesalahan $(\alpha)$ 5\%. Hasil analisis untuk menjawab tujuan penelitian dapat dilihat pada tabel 2. Tabel 2 menunjukkan hasil uji statistik diperoleh hasil bahwa tidak terdapat hubungan antara usia dengan kejadian perdarahan pascasalin $(\mathrm{p}=0,248)$, tidak terdapat hubungan antara paritas dengan kejadian perdarahan postpartum $(\mathrm{p}=0,067)$, terdapat hubungan antara komplikasi kehamilan dengan kejadian perdarahan postpartum $(\mathrm{p}=0,049)$ dan ibu yang mengalami komplikasi kehamilan mempunyai peluang 1,9 kali mengalami perdarahan pascasalin dibanding ibu yang tidak mengalami komplikasi kehamilan $(\mathrm{OR}=1,927)$, terdapat hubungan antara anemia dengan kejadian perdarahan postpartum $(\mathrm{p}=0,000)$ dan ibu yang mengalami anemia mempunyai peluang 5,031 kali mengalami perdarahan pascasalin dibanding ibu yang tidak anemia $(\mathrm{OR}=5,031)$, dan tidak terdapat hubungan antara berat janin dengan kejadian perdarahan postpartum $(\mathrm{p}=0,139)$.

\section{Pembahasan}

Perdarahan merupakan kasus kebidanan paling diwaspadai dan dapat terjadi pada ibu dalam masa persalinan. Faktor - faktor terjadinya perdarahan pascasalin adalah faktor langsung dan faktor predisposisi. Faktor predisposisi terjadinya perdarahan pascasalin antara lain adalah paritas, berat bayi lahir, jarak kehamilan dan riwayat perdarahan postpartum (Bobak, 2004). 
Tabel 2.

Hubungan usia, paritas, komplikasi, anemia, dan berat janin dengan perdarahan pascasalin

\begin{tabular}{lccccccccc}
\hline \multirow{2}{*}{ Variebel } & \multicolumn{2}{c}{ Kelompok Kasus } & \multicolumn{2}{c}{ Kelompok Kontrol } & \multicolumn{2}{c}{ Total } & Nilai & \multirow{2}{*}{ OR } & \multirow{2}{*}{ CI 95\% } \\
\cline { 2 - 8 } & $\mathbf{n}$ & $\mathbf{\%}$ & $\mathbf{n}$ & $\mathbf{\%}$ & $\mathbf{n}$ & $\mathbf{\%}$ & $\boldsymbol{P}$ & & \\
\hline Usia & 23 & 43,4 & 63 & 52,9 & 86 & 50 & 0,248 & 0,681 & $0,35-1,30$ \\
$\quad$ Berisiko & 23 & 43,4 & 63 & 52,9 & 86 & 50 & 0,248 & 0,681 & $0,35-1,30$ \\
$\quad$ Tidak Berisiko & 30 & 56,6 & 56 & 47,1 & 86 & 50 & & & \\
$\quad$ Jumlah & 53 & 30,8 & 119 & 69,2 & 172 & 100 & & & \\
Paritas & & & & & & & & & \\
$\quad$ Berisiko & 19 & 65,5 & 67 & 46,9 & 86 & 50 & 0,067 & 2,155 & $0,93-4,95$ \\
$\quad$ Berisiko rendah & 10 & 34,5 & 76 & 53,1 & 86 & 50 & & & \\
$\quad$ Jumlah & 29 & 16,9 & 143 & 83,1 & 172 & 100 & & & \\
Komplikasi & & & & & & & & & \\
Ada & 33 & 61,1 & 53 & 44,9 & 86 & 50 & 0,049 & 1,927 & $1,00-3,71$ \\
Tidak & 21 & 38,9 & 65 & 55,1 & 86 & 50 & & & \\
Jumlah & 54 & 31,4 & 118 & 86,6 & 172 & 100 & & & \\
Anemia & & & & & & & & & \\
Anemia & 70 & 63,6 & 16 & 25,8 & 86 & 50 & 0,000 & 5,031 & $2,52-10,01$ \\
Tidak Anemia & 40 & 36,4 & 46 & 74,2 & 86 & 50 & & & \\
Jumlah & 110 & 64,0 & 62 & 36,0 & 172 & 100 & & & \\
Berat Janin & & & & & & & & & \\
Besar ( $\geq$ 4 kg) & 2 & 25 & 84 & 51,2 & 86 & 50 & 0,148 & 3,150 & $0,618-16,06$ \\
Tidak besar (<4 kg) & 6 & 75 & 80 & 48,8 & 86 & 50 & & & \\
Jumlah & 8 & 4,7 & 164 & 95,3 & 172 & 100 & & & \\
\hline
\end{tabular}

\section{Komplikasi kehamilan dan perdarahan pascasalin}

Hasil analisis hubungan antara komplikasi kehamilan dengan perdarahan pascasalin diperoleh, dari 86 ibu pascasalin berasal dari ibu yang memiliki komplikasi kehamilan sebanyak $61,1 \%$ orang mengalami perdarahan. Sedangkan, diantara ibu tidak memiliki komplikasi kehamilan terdapat 21ibu pascasalin 38,9\% yang mengalami perdarahan pascasalin. Terdapat hubungan antara komplikasi kehamilan dengan kejadian perdarahan postpartum. Ibu yang mengalami komplikasi kehamilan mempunyai peluang 1,9 kali mengalami perdarahan pascasalin dibanding ibu yang tidak mengalami komplikasi kehamilan.

Komplikasi kehamilan merupakan permasalahan yang timbul selama kehamilan, baik itu disebabkan karena adanya kehamilan itu sendiri, atau permasalahan yang telah ada sebelum kehamilan dan menjadi berat akibat adanya kehamilan. Riwayat obstetri yang buruk pada akhir kehamilan dan awal persalinan sering kali menjadi faktor risiko untuk timbulnya komplikasi pascasalin. Royal College of Obstetricians and Gynaecologists (2013) menyatakan, faktor risiko terjadinya perdarahan pascasalin dapat disebabkan adanya faktor risiko sebelum terjadinya kehamilan, meliputi; riwayat perdarahan pascasalin, memiliki IMT lebih dari 35, paritas >3, gemelly, etnis asia selatan, placenta previa, solutio plasenta, preeklamsi, hipertensi dan anemia. Penelitian Smith R.J (2017) tentang faktor risiko dari perdarahan pascasalin, hipertensi pada kehamilan dan persalinan berpotensi untuk timbulnya perdarahan pascasalin (OR 1,7; 95\% CI: $1,2-2,1)$.

Kasus perdarahan yang terjadi, sebagian besar disebabkan karena seringkali lalai melakukan 3T yaitu terlambat mengambil keputusan, telambat mancapai rumah sakit rujukan dan rujukan tidak efektif serta terlambat mendapatkan pertolongan yang adekuat di rumah sakit rujukan (Dinas Kesehatan Provinsi Lampung, 2013). Menghindari kelalaian tersebut, perlu ditanamkan kepada semua tenaga kesehatan khususnya pada pelayanan kebidanan bahwa setiap ibu hamil memiliki risiko untuk mengalami komplikasi selama kehamilan dan persalinan. Komplikasi pada kasus kebidanan seharusnya dapat ditangani dengan 
memperhatikan antara lain; melakukan kewaspadaan pada tiap komplikasi obstetri yang dapat diprediksi, akses yang mudah bagi ibu hamil dan bersalin terhadap pelayanan kesehatan yang berkualitas, dan ketersedian pelayanan berkualitas beserta petugasnya saat 24 jam pertama masa persalinan.

\section{Anemia kehamilan dan perdarahan pascasalin}

Hasil analisis hubungan antara anemia dengan perdarahan pascasalin diperoleh dari $86 \mathrm{ibu}$ pascasalin berasal dari ibu yang mengalami anemia sebanyak 63,6\% mengalami perdarahan. Sedangkan diantara ibu yang tidak mengalami anemia terdapat 36,4\% ibu bersalin yang mengalami perdarahan pascasalin. Terdapat hubungan antara anemia dengan kejadian perdarahan postpartum. Ibu yang mengalami anemia mempunyai peluang 5,031 kali mengalami perdarahan pascasalin dibanding ibu yang tidak anemia.

Anemia merupakan salah satu masalah kesehatan masyarakat yang sebagian besar di negara berkembang dengan prevalensi melebihi $50 \%$ terjadi selama kehamilan. Anemia dianggap meningkatkan resiko perdarahan pascasalin dan berkontribusi pada 40 - 43\% kematian ibu di Afrika dan Asia. Hasil penelitian ini sama dengan penelitian (Kavle, Stoltzfus, Witter, Tielsch, Khalfan, \& Caulfield, 2008), terkait pengaruh anemia terhadap perdarahan pascasalin dari analisis bivariat diperoleh peningkatan kehilangan darah saat melahirkan dan postpartum sangat terkait dengan keparahan anemia ibu $(p=0,02)$. Penelitian lain yang dilakukan di RSUD Wonogiri, diperoleh sebanyak 32,4\% ibu mengalami anemia selama hamil, dimana 45,5\% mengalami perdarahan postpartum. Terdapat hubungan antara anemia dalam kehamilan dengan perdarahan postpartum karena atonia uteri (Wuryanti, 2010).

Ibu dengan anemia dapat mendahului tejadinya perdarahan pascasalin. Kondisi ini disebabkan terjadinya proses haemodelusi selama kehamilan yang berdampak darah seakan - akan mengalami pengenceran. Dampak peristiwa ini menyebabkan oksigen yang diikat dalam darah kurang sehingga jumlah oksigen yang dikirim ke uterus berkurang. Hal ini menyebabkan otot-otot uterus tidak dapat berkontraksi dengan adekuat sehingga pada akhirnya dapat menyebabkan perdarahan pascasalin (Madforth \& dkk, 2011).

Kasus perdarahan pascasalin pada penelitian ini sangat mungkin disebabkan karena status anemia responden yaitu sebanyak $64 \%$ mengalami anemia. Hanya saja yang perlu diteliti lebih mendalam adalah apakah anemia yang terjadi disebabkan karena proses haemodelusi saat kehamilan atau anemia telah terjadi sebelum kehamilan. Hal ini penting diketahui untuk melakukan pencegahan sedini mungkin. Oleh karena itu, perlu kiranya memperhatikan status anemia pada wanita usia reproduksi sebagai salah satu antisipasi pencegahan komplikasi baik pada masa kehamilan maupun pascasalin.

\section{Simpulan dan saran}

Hasil penelitian menyimpulkan bahwa ibu hamil dan bersalin yang mengalami komplikasi kehamilan mempunyai peluang meningkatkan 1,9 kali mengalami perdarahan pascasalin dibanding ibu yang tidak mengalami komplikasi kehamilan dan Ibu hamil dan bersalin yang mengalami anemia mempunyai peluang meningkatkan 5,0 kali mengalami perdarahan pascasalin dibanding ibu yang tidak anemia. Perlu upaya menurunkan dan mencegah perdarahan poscasalin dengan mencegah terjadinya berbagai komplikasi kehamilan dan anemia kehamilan. Ibu hamil hendaknya melakukan kunjungan kehamilan dengan rutin ke Puskesmas atau tenaga kesehatan untuk deteksi dini dan penanganan segera temuan komplikasi kehamilan dan anemia. 


\section{Referensi}

Belfort, A. M. (2017). Overview of postpartum hemorrhage, obstetrics, gynekology and womens health. associate clinical professor of obstetrics. gynecology and reproductive biology. Retrieved September 17, 2017, from Journals reviewed by up to date: https:/www.uptodate.com/contents/overview-of-postpartumhemorrhage/print.

Bellieni, C. (2016). The best age for pregnancy and undue pressures. J family reprod health. 10(3), 104-107. Retrieved from: https://www.ncbi.nlm.nih.gov/pmc/articles/PMC5241353/.

Bobak, L. (2004). Buku ajar keperawatan maternitas. Jakarta: Buku Kedokteran EGC.

Cunningham, \& dkk. (2000). Obstetri williams. Jakarta: Buku Kedokteran EGC.

Dinas Kesehatan Provinsi Lampung. (2013). Profil kesehatan provinsi lampung tahun 2012. Bandar Lampung: Dinas Kesehatan Provinsi Lampung.

Eriza, N., Defrin, \& Lestari, Y. (2015). Hubungan perdarahan postpartum dengan paritas di RSUP Dr. M. Djamil periode 1 Januari 2010 - 31 Desember 2012. Jurnal Kesehatan Andalas. 4(3), 765-771. DOI: https://doi.org/10.25077/jka.v4.i3.p\%25p.2015

Friyandini, F., Lestari, Y., \& Utama, B. I. (2015). Hubungan kejadian perdarahan postpartum dengan faktor risiko karakteristik ibu di RSUP Dr. M. Djamil Padang pada januari 2012 - april 2013. Jurnal Kesehatan Andalas, 4.

Holmes, D., \& Philip, N. B. (2011). Buku ajar asuhan kebidanan . Jakarta: EGC.

Janet, M., \& dkk. (2011). Kebidanan oxford "dari bidan untuk bidan". Jakarta: EGC.

Kavle, J. A., Stoltzfus, R. J., Witter, F., Tielsch, J. M., Khalfan, S. S., \& Caulfield, L. E. (2008). Association between anaemia during pregnancy and blood loss at and after delivery among women with vaginal births in pemba island, zanzibar, tanzania. Jurnal of health, population, and nutrition. 40-232.

Kementrian Kesehatan RI. (2016). Profil kesehatan indonesia tahun 2015. Jakarta: Kementrian Kesehatan RI.

Ononge, S., Mirembe, F., Wandabwa, J., \& Campbell, O. (2016). Incidence and risk factors for postpartum hemorrhage in uganda. Retrieved September 7, 2017, from Reprod Health: https://www.ncbi.nlm. nih.gov/pmc/articles/PMC4832492/

Oxorn, H., \& William, R. F. (2010). Ilmu kebidanan patologi \& fisiologi . Yogyakarta: Yayasan Essentia Medica.

Oyelese, Y., \& Ananth, C. V. (2010). Postpartum hemorrhage: epidemiology, risk factors, and causes. Retrieved September 7, 2017, from Clinical Obstetrics and Gynecology: https:/doi.org/10.1097/GRF.0b013e3181cc406d

Rifdianilzfa. (2017). The effect of parity, birth weight babies, pregnancy interval and a history of hemorrhage with the incidence of postpartum hemorrhage (case study in the RSUD Ngudi Waluyo Wlingi Blitar 2014).

ROGC. (2013). Heavy bleeding after birth (postpartum haemorrhage). Retrieved Agustus 20, 2017, from https://www.heavy-bleeding-after_birth.com

Smith, J. (2017). Postpartum hemorrhage emedicine. Medscape.

Stickler, T., \& Schulman, S. J. (2018). Health risks associated with pregnancy. Retrieved from Healthline.

Wuryanti, A. (2010). Hubungan anemia dalam kehamilan dengan perdarahan postpartum karena atonia uteri di RSUD wonogiri. Institusional Repository Universitas Sebelas Maret. Retrieved from: https://eprints.uns.ac.id/107/ 